\title{
Educating Scientists During Hard Times
}

\author{
C. C. Chancey, Editor \\ American Journal of Undergraduate Research \\ University of Northern lowa \\ Cedar Falls, lowa 50614-0150 USA
}

The current financial recession is finding its way into colleges and universities across the world. Resources for teaching and research are becoming more limited, and students are rethinking whether they can afford to study science, given its serious time commitment. Recessions-and worse-are a matter of history, but this is the first serious world-wide downturn for our global technological society. Are resources to educate the future scientific workforce at risk? Yes. Should they be? No, not if we are wise.

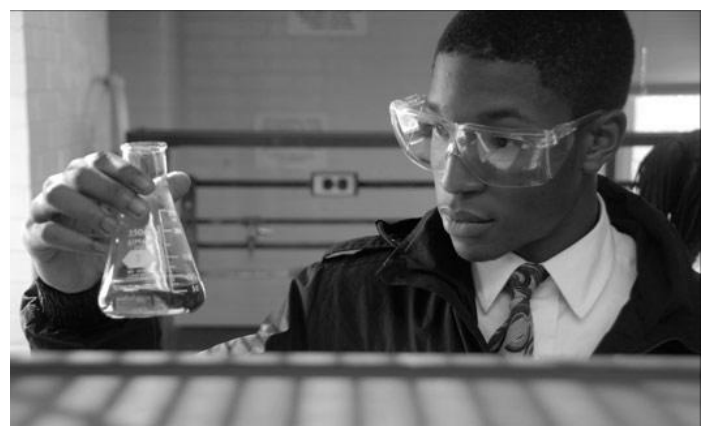

Editorials in global newspapers such the Financial Times (of London) have highlighted the continuing and accelerating need for science and technology graduates, even in these difficult times. President-Elect Obama continues to champion alternative energy technologies, and vows to make a significant federal investment in them. Even if one-half of what Obama proposes comes to fruition, the workforce requirements will be a challenge to meet.

It is a sober truism that Western society, scientifically and technologically empowered like no previous civilization, is nearly blind to the workforce requirements that empower it. It is a corollary that the practical necessity for new chemists,

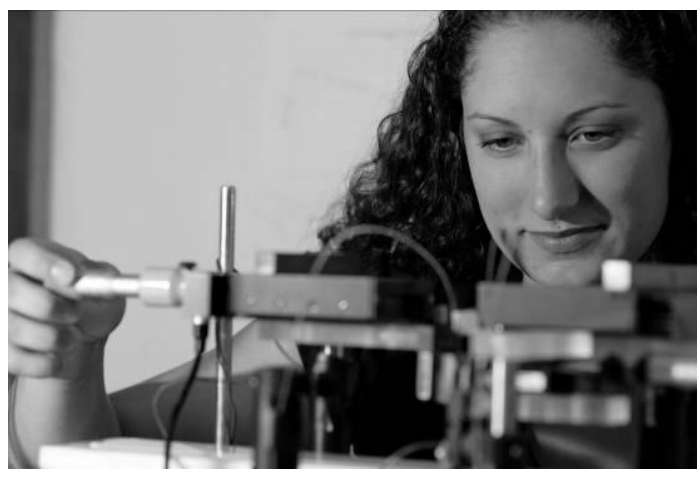

engineers, mathematicians, physicists and biologists is as great now as it has ever been.

Those of us in the US and the other OECD economies must meet this challenge on two fronts. First, every college and university must actively work to increase undergraduate enrollments in STEM disciplines. This will require new thinking on ways to attract young women and underenrolled minorities to science. Second, college and university administrators must think strategically how their institutions can improve the chances of matriculating more first-year students interested in STEM disciplines. This will require some new thinking, particularly in the US.

We have reasons to be cautiously optimistic: No society has ever had greater resources than ours, and a higher percentage of the world's citizens now complete a secondary education than ever before in history. These facts provide good ground on which to stand in leveraging greater success in educating scientists. In this regard, we should be ambitious like Archimedes who praised the power of the lever: "Give me a place to stand and I will move the earth." 